\title{
Commercial mechanism analysis and benefit evaluation of energy storage
}

\author{
WANG Zhiqiang ${ }^{1}$, WANG Xiaolong ${ }^{1, \mathrm{a}}$ and MAO Yuyang ${ }^{1}$ \\ ${ }^{1}$ State Key Laboratory of Alternate Electrical Power System with Renewable Energy Sources (North China Electric Power University), \\ Changping District, Beijing 102206, China
}

\begin{abstract}
With the increasing proportion of renewable energy in the energy system, problems such as power fluctuation and difficulty in frequency and voltage regulation are aggravated. The application of energy storage can alleviate these problems, and reasonable commercial mechanism analysis and benefit evaluation can promote the adoption of energy storage technology by the society. In this paper, the commercial mechanism is divided into four dominant modes based on market subjects, the main application scenarios of each mode are given, and the dominant modes are compared from the perspectives of technology, economy and society. Finally, the benefit evaluation models of each application scenario are constructed. The content of this paper has a certain reference value for investors of energy storage devices.
\end{abstract}

\section{Introduce}

In the context of advocating the development of renewable energy, the proportion of renewable energy in the energy system is gradually increasing. This is a process with opportunities and challenges. Although it optimizes the energy structure, it makes the power system highly volatile. It also makes the frequency and voltage regulation capabilities of the original system difficult to cope with the challenges. In this case, the energy storage technology shows obvious advantages and is a research object with great development potential [1]. Among them, a good commercial mechanism can expand the benefits of investment, so it is important to analyse the commercial mechanism of energy storage and quantitatively evaluate benefits.

Based on the subjects in the energy storage market, this paper divides the commercial mechanism into the power generation company dominant mode, the power grid company dominant mode, the user dominant mode and the third-party dominant mode, classifies them through two principles, then obtains the main application scenarios under each dominant mode, and compares the dominant modes from the perspectives of technology, economy and society. Because the cost and revenue of different application scenarios are different, the cost model and revenue model of each application scenario are established, and the benefit evaluation models are given by combining the net present value method. The commercial mechanism analysis and benefit evaluation of energy storage have a certain reference value for the investors of energy storage devices.

\section{COMMERCIAL MECHANISM}

For energy storage project, the market subject can be roughly divided into power generation company, power grid company, user and third-party (it is usually energy storage company), above the market subjects can act as the role of investor, thus can roughly divides the commercial mechanism of energy storage into the power generation company dominant mode, the power grid company dominant mode, the user dominant mode and the third-party dominant mode.

\section{1 'I invest, I gain’}

The first three dominant modes in grasp the 'I invest, I gain' principle [2]: each dominate party bear the cost of the energy storage projects from the beginning, including the cost of buying energy storage devices, installation cost, access cost, operation cost and maintenance cost, etc [3], but the revenue generated is owned by the dominant party. The dominant party can choose investment location, but some application scenarios have drawbacks in terms of cost and revenue, as follows:

1) For application scenarios where energy storage devices are invested in remote places, such as the gridside energy storage dominated by power generation company, there are the following cost drawbacks: a. additional access costs and installation costs are required for the construction of energy storage devices on nonlocal sites; b. high operation and maintenance costs are unavoidable because human and material resources are from other subjects; c. it is more difficult to win the favour of investors in financing, which requires the cost of time and funds, resulting in the increase of financing cost.

\footnotetext{
a WANG Xiaolong: 15601259722@163.com
} 
2) For the power-side energy storage dominated by power grid company or user, part of the revenue comes from reducing power shortage by improving the output characteristics of the renewable generator. However, this process requires technical and data support from professionals of the power generation company, which will surely lead to the transfer of part of the revenue to the power generation company.

3) For the grid-side energy storage dominated by power generation company or user, the revenue mainly comes from power peak regulation. However, the two scenarios need to obtain grid-side load data to realize power peak regulation, so a part of the revenue will surely be transferred to the power grid company.

4) For the user-side energy storage dominated by power generation company or power grid company, the two scenarios in order to get the user-side load data also will lose some revenue. In addition, reducing electricity cost and power interruption loss need energy storage system has fast response speed, however power generation company or power grid company solely responsible for energy storage projects, will increase the scheduling time, as a result, revenue will decline.

To sum up, there are three high-value application scenarios of "I invest, I gain": the power-side energy storage dominated by power generation company, the grid-side energy storage dominated by power grid company and the user-side energy storage dominated by user.

\section{2 'Who benefits, who pays'}

In the third-party dominant mode, the third-party is solely responsible for entire energy storage project, adhering to the principle of 'Who benefits, who pays' [2]: the thirdparty bears the cost of the energy storage projects from the beginning, and become the capital ownership, rent energy storage devices to power-side and grid-side and user-side in public. If the three sides need to hire the energy storage devices of the third-party, the negotiations are needed to make up for the cost of third-party and combined with the profits of third-party due to the cost, part of the income from the three sides will be paid [4]. Figure 1 illustrates the relationship in the third-party dominant mode.

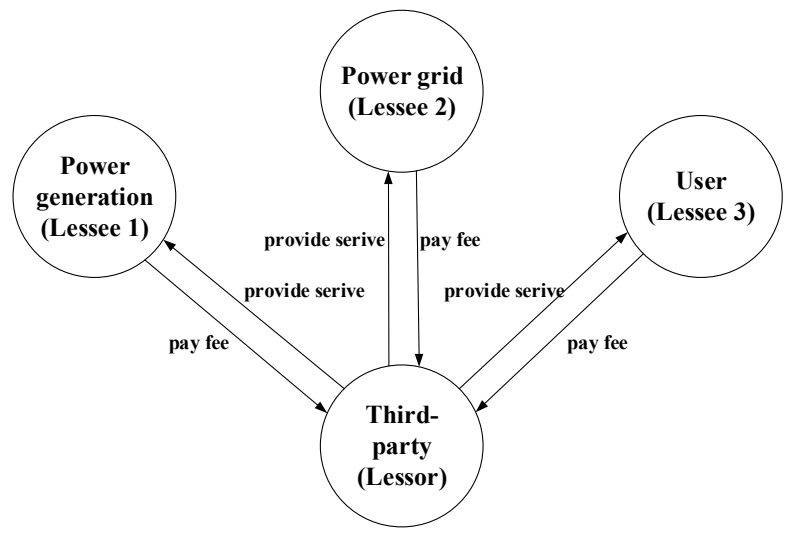

Fig 1. Relationship in the third-party dominant mode

The third-party can also choose investment location, but its main application scenario is the grid-side energy storage dominated by the third-party, reasons are as follows:

1) Most of the revenue of energy storage come from the arbitrage of peak-valley difference after peak clipping and valley filling. However, the power-side energy storage dominated by the third-party needs to rent the stored energy to the power grid company and users, which increases the cost and time.

2) The revenue comes from installing energy storage on the grid-side is extremely obvious.

3) Energy storage devices can promote the power system to better absorb renewable energy, which is just in line with the national call. Generally, the power grid company is central enterprises, and they are more willing to be the installation site of energy storage devices [5].

\subsection{Comparison}

The above four business mechanisms have their own advantages from the perspectives of technology, economy and society. The specific comparison is as follows:

1) Technology: a. the third party is generally an energy storage company, which has a deeper grasp of energy storage technology and is more proficient in the use of energy storage devices and the repair of failure; $b$. the energy storage devices of first three dominant modes are for internal use only, cause the devices are often idle, but the third party dominant mode interconnects power-side, grid-side and user-side, make the object supplied by the energy storage system is no longer a single, greatly improve the equipment utilization.

2) Cost: a. the third party is generally an energy storage company, and the energy storage devices can be obtained only at the cost price. However, investors in the first three dominant modes need to purchase the energy storage devices in the energy storage market at the market price; $b$. the first three dominant modes do not need to install the energy storage devices in remote places, investors do not need to rely on site and human resources from other participants, and the long-distance transportation of materials is avoided, thus leading to a significant decrease in access cost and installation cost; $\mathrm{c}$. in the power generation company dominant mode, the electric energy can be internally supplied and then obtained at the cost price, but in the other three dominant modes, electric energy needs to be purchased from the electricity selling company at the market price; $d$. the power generation company dominant mode also avoids the capacity electricity price in the two-part electricity price because the electric energy can be supplied internally; e. because the third party has technical advantages and is skilled in the use, inspection and maintenance of devices, the operation and maintenance costs of the third party are reduced.

3) Revenue: the revenue extracted from energy storage is definitely uncertain. For example, the revenue of energy storage on the power-side by promoting better absorption of renewable energy is greatly affected by the external environment, so are the revenues on the grid-side and the user-side. Due to the complex and changeable influencing factors, the revenue fluctuates widely. In the first three 
dominant modes, the revenue source of the investor is relatively single, resulting in high volatility. In the thirdparty dominant mode, the revenue can be extracted from the power-side, the grid-side and the user-side, so that the uncertainty of the revenue will be significantly reduced.

4) Society: a. the first three dominant modes are relatively independent, but the third-party dominant mode establishes a close network, gathers all kinds of scattered resources, maximizes the utilization of resources through cooperation and negotiation, and then realizes sustainable development; $b$. the investment and construction of the energy storage system under the third-party dominant mode is concentrated. Compared with power-side, gridside and user-side, the cost is greatly reduced from the perspective of the total social cost, thus speeding up the process of industrial upgrading; c. the third-party dominant model perfectly in line with the principle 'communication, cooperation, pragmatic and efficient', and the model fully embodies the concept of 'responsibility', positive negotiation between the parties, in turn, determine their respective responsibilities, then each party complete the agreed tasks within its own jurisdiction, to ensure project to complete within the time required with high quality [4]; d. in the third-party dominant mode, all participants are benefit subjects, which can promote the active cooperation among participants and promote social harmony.

\section{Benefit evaluation}

In order to provide reference for investors of energy storage and lay a foundation for determining future research direction of energy storage technology, it is necessary to quantify the benefits of energy storage in practice. This paper evaluates the benefits of the application scenarios obtained in the previous chapter from the aspects of cost and revenue.

\subsection{The power-side energy storage dominated by power generation company}

In this application scenario, costs include system device cost $C_{1}$, installation cost $C_{2}$, electricity cost $C_{3}$ and operation and maintenance cost $C_{5}$, and revenues include avoided penalty for power shortage $B_{1}$ and avoided power abandonment loss $B_{2}$ [6]. The specific benefits are as follows:

$$
\begin{gathered}
Y_{1}=\sum_{i=1}^{T}\left(B_{1 i}+B_{2 i}-C_{1 i}-C_{2 i}-C_{3 i}-C_{5 i}\right)(1+j)^{-i} \\
\mathrm{C}_{1}=2 k_{d} P_{\text {rate }}+k_{x} E_{\text {rate }} \\
\mathrm{C}_{2}=N k_{e} T_{e} \\
C_{3}=\sum_{i=1}^{8760} W_{i} k_{c . i} \\
C_{5}=\left(k_{y}+k_{j}+k_{w}\right) P_{\text {rate }} \\
B_{1}=k_{\text {pun }} E_{\text {lack }} \\
B_{2}=k_{\text {loss }} E_{\text {loss }}
\end{gathered}
$$

Where, $K_{d}$ and $K_{x}$ are the unit prices of the energy conversion device and the energy storage devices respectively; $P_{\text {rate }}$ and $E_{\text {rate }}$ are the rated power and rated capacity respectively. $N$ is the number of technical personnel employed; $K_{e}$ is the daily remuneration; $T_{e}$ is the number of days required for the installation. $W_{i}$ is the electricity required by the investor in hour $i ; K_{c . i}$ is the cost price of electricity in hour $i . K_{y}$ is the unit operating cost; $K_{i}$ is the unit inspection cost; $K_{w}$ is the unit maintenance cost. $K_{\text {pum }}$ is the penalty for lack of unit electricity; $E_{\text {lack }}$ is the total power shortage in a year. $K_{\text {loss }}$ is the loss of unit power abandonment; $E_{\text {loss }}$ is the total amount of power abandoned in a year.

\subsection{The grid-side energy storage dominated by power grid company}

In this application scenario, costs include system device $\operatorname{cost} C_{1}$, installation cost $C_{2}$, electricity $\operatorname{cost} C_{3}$, electrical capacity charge cost $C_{4}$ and operation and maintenance cost $C_{5}$, and revenues includes delaying power grid and peak-shaving unit upgrade revenue $B_{3}$, reducing power grid line loss $B_{4}$ and financial incentive funds $B_{5}$ [7][8]. The specific benefits are as follows:

$$
\begin{gathered}
Y_{2}=\sum_{i=1}^{T}\left(B_{3 i}+B_{4 i}+B_{5 i}-C_{1 i}-C_{2 i}-C_{3 i}{ }^{\prime}-C_{4 i}-C_{5 i}\right)(1+j) \\
C_{3}{ }^{\prime}=\sum_{i=1}^{8760} W_{i} k_{s . i} \\
C_{4}=\sum_{i=1}^{12} k_{r . i} P_{\max . i} \\
B_{3}=P_{\text {inf }} k_{\text {inf }}\left(1-\frac{1}{e^{\Delta T p}}\right) \\
B_{4}=\frac{2 P_{H} \Delta P_{H}-\Delta P_{H}^{2}}{u^{2} \cos ^{2} \theta} R_{H} t_{H} k_{H}+\frac{2 P_{L} \Delta P_{L}-\Delta P_{L}^{2}}{u^{2} \cos ^{2} \theta} R_{L} t_{L} k_{L} \\
B_{5}=k_{f} \Delta P_{f}
\end{gathered}
$$

Where, $K_{s . i}$ is the unit market price of the electricity in hour $i . K_{r . i}$ is the unit electrical capacity charge in month $i ; P_{\max . i}$ is the average maximum load capacity within 15 minutes at the peak of the month $i . P_{i n f}$ is the delay capacity; $K_{\text {inf }}$ is the unit upgrade cost; $P$ is the annual interest rate. $P_{H}$ and $P_{L}$ are the power at peak load and trough load respectively; $R_{H}$ and $R_{L}$ are respectively the equivalent resistance at peak load and trough load; $t_{H}$ and $t_{L}$ are respectively the discharge time at peak load and charging time at trough load; $k_{H}$ and $k_{L}$ are the price of peak load and trough load respectively. $K_{f}$ is the bonus for reducing unit peak load.

\subsection{The user-side energy storage dominated by user}

In this application scenario, costs include system device $\operatorname{cost} C_{1}$, installation cost $C_{2}$, electricity $\operatorname{cost} C_{3}$, , electrical capacity charge cost $C_{4}$ and operation and maintenance $\operatorname{cost} C_{5}$, and revenues include the revenue from reducing capacity of distribution transformers dedicated to large users $B_{6}$, reducing distribution transformer loss $B_{7}$, reducing electrical capacity charge $B_{8}$, reducing electricity 
cost $B_{9}$ and reducing power outages loss $B_{10}$ [9]. The specific benefits are as follows:

$$
\begin{gathered}
Y_{3}=\sum_{i=1}^{T}\left(B_{6 i}+B_{7 i}+B_{8 i}+B_{9 i}+B_{10 i}-C_{1 i}-C_{2 i}-C_{3 i}{ }^{\prime}-C_{4 i}-C_{5 i}\right)(1+j)^{-i} \\
B_{6}= \begin{cases}k_{p} P_{\text {rate }} & P_{\text {rate }} \leq P_{f}-P_{a} \\
k_{p}\left[2\left(P_{f}-P_{a}\right)-P_{\text {rate }}\right] & P_{\text {rate }}>P_{f}-P_{a}\end{cases} \\
B_{7}=\sum_{i=1}^{8760} \frac{\left[P_{i}^{2}-\left(P_{i}-\Delta P_{i}^{+}+\Delta P_{i}^{-}\right)\right] P_{k} k_{s . i}}{\left(S_{N} \cos \varphi\right)^{2}} \\
B_{8}= \begin{cases}k_{r} P_{\text {rate }} \\
k_{r}\left[\begin{array}{ll}
\left.2\left(P_{f}-P_{a}\right)-P_{\text {rate }}\right] & P_{\text {rate }}>P_{f}-P_{a}
\end{array}\right. \\
B_{9}=\sum_{i=1}^{8760}\left(\Delta P_{i}^{+}-\Delta P_{i}^{-}\right) k_{s . i}\end{cases} \\
B_{10}=\sigma T_{s}\left(1-A_{s}\right) P_{0} \lambda_{s} \frac{h}{24}+\left[\lambda_{s}-\lambda_{s} \lambda_{b}\left(r_{s}+r_{b}\right)\right] k_{\lambda}(19)
\end{gathered}
$$

Where, $k_{p}$ is the unit price of distribution transformers; $P_{a}$ is the average load. $P_{k}$ is short circuit loss of distribution transformer; $S_{N}$ is the rated capacity of distribution transformers. $\sigma$ is the evaluation rate of production revenue loss in case of power failure; $T_{s}$ is annual production hours; $A_{s}$ is the power supply reliability index; $P_{0}$ is the power to maintain production; $\lambda_{s}$ is the power failure rate without the energy storage device; $h$ is the number of hours in a day when the electric quantity of the energy storage device is sufficient to compensate for the power shortage; $\lambda_{b}$ is the failure rate of the energy storage device; $r_{s}$ and $r_{b}$ are respectively the recovery time of power supply and the repair time of the energy storage device; $k_{\lambda}$ is the equipment damage loss caused by each power failure.

\subsection{The grid-side energy storage dominated by the third-party}

In this application scenario, costs include the cost price of device $C_{1}$ ', installation $\operatorname{cost} C_{2}$, electricity $\operatorname{cost} C_{3}$,' electrical capacity charge cost $C_{4}$ and operation and maintenance cost $C_{5}$ '. The revenues are extracted from the power-side, grid-side and user-side, so the revenues in this scenario include all the revenues. The specific benefits are as follows:

$$
\begin{gathered}
Y_{4}=\sum_{i=1}^{T}\left(\begin{array}{c}
B_{1 i}+B_{2 i}+B_{3 i}+B_{4 i}+B_{5 i}+B_{6 i}+B_{7 i}+B_{8 i}+B_{9 i}+B_{10 i} \\
-C_{1 i}{ }^{\prime}-C_{2 i}{ }^{\prime}-C_{3 i}{ }^{\prime}-C_{4 i}-C_{5 i}{ }^{\prime}
\end{array}\right)(1+j)^{-i} \\
\mathrm{C}_{1}^{\prime}=2 k_{d}{ }^{\prime} P_{\text {rate }}+k_{x}^{\prime} E_{\text {rate }} \\
\mathrm{C}_{2}{ }^{\prime}=N k_{e} T_{e}+k_{c} T+k_{t} S \\
C_{5}^{\prime}=\mu\left(k_{y}+k_{j}+k_{w}\right) P_{\text {rate }}
\end{gathered}
$$

Where, $k_{d}$ ' and $k_{x}$ ' are the unit cost price of the energy conversion device and the energy storage devices respectively; $k_{c}$ is the annual rent of the site of the power grid company; $T$ is the whole life cycle of the energy storage device; $k_{t}$ is the transportation cost; $S$ is the distance between the third-party and the power grid company. $\mu$ is the reduction rate of operation and maintenance costs caused by the technical advantage of third-party.

\section{CONCLUSION}

To sum up, a good commercial mechanism can promote energy storage to be better accepted by the society, and the benefit evaluation that fits the reality lays the data foundation for the commercial mechanism analysis. At the present stage, energy storage technology and its application still have a lot of shortcomings, such as high cost, performance is still not up to the requirements, hybrid energy storage control system is not mature. Only by solving these problems in the future, can energy storage technology integrate into the society with a higher proportion and a higher quality.

\section{References}

1. HAN Xiaojuan, AI Yaoyao and LI Xiangjun. Application Value of Energy Storage Systems in the PowerGrid and Its Commercial Modes[J]. Power Generation Technology, 2018, 39(01): 77-83.

2. YANG Jianlin, HUANG Yichao, FEI Fei, et al. Research of Economic Benefits of Energy Storage Technique under Different Business Operational Modes[J]. Electrical Engineering, 2018, 19(03): 8084.

3. Business Model and Financing of Energy Storage Enterprises[J]. The World of Inverters, 2018(06): 3335.

4. HUANG Jiyuan, YANG Jun, XU Hui, et al. Commercial Operation Mode of Megawatt Battery Energy Storage System in Distribution Network[J]. Electrical \& Energy Management Technology, 2018(17): 5-8+17.

5. XU Hui, HUANG Jiyuan, YANG Jun, et al. Research on the Business Mode of the Network Side Electrochemical Energy Storage System Based on Multi-stakeholders[J]. Electrical \& Energy Management Technology, 2018(24): 85-90.

6. HUANG Jiyuan, LIU Bo, LI Xinran, et al. Economic Analysis of Energy Storage Participating in Fast Frequency Regulation[J]. Electrical \& Energy Management Technology, 2017(23): 65-70.

7. SU Hu, LI Jun, WU Yuguang, et al. Assessment of the Economic Value of the Energy Storage Battery Systems[J]. Journal of Shanghai University of Electric Power, 2013, 29(04): 315-320.

8. XIONG Xiong, YANG Rengang, YE Lin, et al. Economic Evaluation of Large-Scale Energy Storage Allocation in Power Demand Side[J]. Transactions of China Electrotechnical Society, 2013, 28(09): 224230.

9. YAN Zhimin, WANG Chengmin, LIAN Hongbo, et al. Capacity Plan of Battery Energy Storage System in User Side Considering Power Outage Cost[J]. Automation of Electric Power Systems, 2012, 36(11): 50-54. 